\title{
Higher Education and the WTO: Globalization Run Amok
}

\author{
Philip G. Altbach \\ Philip G. Altbach is J. Donald Monan S.J. professor of higher education and \\ director of the Center for International Higher Education at Boston College.
}

Higher education is increasingly seen as a commercial product to be bought and sold like any other commodity. Higher education commercialization has now reached the global marketplace. The World Trade Organization (WTO) is considering a series of proposals to include higher education as one of its concerns, ensuring that the import and export of higher education be subject to the complex rules and legal arrangements of the WTO protocols and free of most restrictions. In the United States, the National Committee for International Trade in Education and a group of mainly for-profit education providers are supporting this initiative. The established higher education community, including the American Council on Education, is not involved in this undertaking. The WTO initiative poses a severe threat to the traditional ideals of the university, as well as to the national and even institutional control of education, and therefore needs careful scrutiny. We are in the midst of a true revolution in higher education, a revolution that has the potential to profoundly change our basic understanding of the role of the university. The implications are immense and as yet little discussed or understood. It is especially alarming, but not surprising, that the U.S. Department of Commerce's Office of Service Industries is behind the effort to commercialize higher education in the United States and worldwide.

I am not arguing against globalization either as a reality or as a concept. Higher education institutions everywhere are subject to global trends-massification and all of its implications, the impact of the new communications technologies, accountability of academic institutions to government, an increasingly international and mobile academic profession, global research networks, and other phenomena.

Many of these developments link academic institutions and systems globally. The use of English as the lingua franca for scientific communication and for teaching, especially when combined with the Internet, makes communication easier and quicker. The advent of multinational higher education institutions makes it possible to disseminate new curricular and other innovations quickly and to meet the immediate needs of students and the national economies of countries that lack adequate providers of higher education.

For centuries, universities were seen as institutions that provided education in the learned professions (law, medicine, and theology) and scientific disciplines. Universities, as independent and sometimes critical institutions, preserved and interpreted, and sometimes expanded, the history and culture of society. In the 19th century, research was added to the responsibilities of the universities, followed a little later by service to society. Academic institutions were, in the main, sponsored by the state or the church. Even privately sponsored institutions were defined by the service mission. Higher education was seen as a "public good," as something that provided a valuable contribution to society and was therefore worthy of support.

Universities were places for learning, research, and service to society through the application of knowledge. Academe was afforded a significant degree of insulation from the pressures of society-academic freedomprecisely because it was serving the broader good of society. Professors were often given permanent appointmentstenure-to guarantee them academic freedom in the classroom and laboratory to teach and do research without fear of sanctions from society.

Today, trends such as the rise of the Internet and the globalization of knowledge have the potential for creating severe problems for academic institutions and systems in smaller or poorer nations.

Downsides of Globalization

Today, trends such as the rise of the Internet and the globalization of knowledge have the potential for creating severe problems for academic institutions and systems in smaller or poorer nations. In a world divided into centers and peripheries, the centers grow stronger and more dominant and the peripheries become increasingly marginalized. Inequalities grow more pronounced. There is little leeway for academic systems or individual universities to independently develop in the increasingly competitive and fast moving global higher education scene dominated by the world-class universities in the industrialized countries. The traditional academic center becomes ever stronger and more dominant-mainly in the English-speaking countries of the North (the United States, the United Kingdom, Canada) and in Australia, and in the larger countries of the European Union (notably Germany and France, and to some extent Italy and Spain).

The norms, values, language, scientific innovations, and knowledge products of countries in the center crowd out other ideas and practices. These countries are home not only to the dominant universities and research facilities but also to the multinational corporations so powerful in the 
new global knowledge system. Information technology companies such as Microsoft and IBM, biotechnology and pharmaceutical firms (Merck or Biogen), multinational publishers like Elsevier or Bertelsmann, among others, dominate the new international commerce in knowledge, knowledge-based products, and information technology. Smaller and poorer countries have little autonomy or competitive potential in the globalized world. Globalization in higher education exacerbates dramatic inequalities among the world's universities.

\section{The Commercialization of Knowledge and Higher Education} With the growing commercialization of higher education, the values of the marketplace have intruded onto the campus. One of the main factors is the change in society's attitude toward higher education-which is now seen as a "private good" benefiting those who study or do research. In this view, it seems justified that the users should pay for this service as they would for any other service. The provision of knowledge becomes just another commercial transaction. The main provider of public funds, the state, is increasingly unwilling or unable to provide the resources needed for an expanding higher education sector. Universities and other postsecondary institutions are expected to generate more of their funding. They have had to think more like businesses and less like educational institutions.

In this context a logical development is the privatization of public universities - the selling of knowledge products, partnering with corporations, as well as increases in student fees. The proliferation of private academic institutions of all kinds, especially in the for-profit sector, is another byproduct of commercialization. Education companies, some of which call themselves universities, sell skills and training, awarding degrees or certificates to customers (students). Research is seen as a fungible product rather than an inquiry conducted to advance the frontiers of science.

\section{The WTO Enters the Equation}

In these changed circumstances, it is not surprising that those motivated by commerce, in government and in the private sector, would concern themselves with ensuring that "knowledge products" are freely traded in the international marketplace. If these interest groups have their way, higher education in all of its manifestations will be subject to free trade discipline just like bananas or airliners. The rules of the WTO, and its related General Agreement on Trade and Services (GATS), it must be remembered, are legally binding. There is a danger that regulations relating to higher education will be included in an international agreement "under the radar" and without much analysis. When something becomes part of the WTO regime requirements and regulations, it is subject to complex arrangements. The implications for higher education are immense, not only because of a new set of international regulations but be- cause the university will be defined in an entirely new way: the overriding goal of GATS and the WTO is to guarantee market access to educational products and institutions of all kinds.

The trade in higher education is, of course, more difficult to codify than bananas. But efforts are now under way to do precisely this-to create a regime of guidelines and regulations to institute free trade in higher education. The WTO would help to guarantee that academic institutions or other education providers could set up branches in any country, export degree programs, award degrees and certificates with minimal restriction, invest in overseas educational institutions, employ instructors for their foreign ventures, set up educational and training programs through distance technologies without controls, and so on.

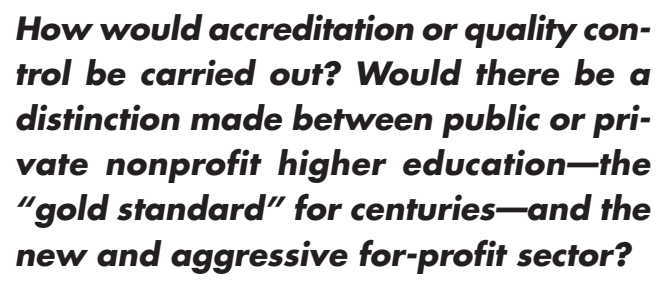

Educational products of all kinds would be freely exported from one country to another. Copyright, patent, and licensing regulations, already part of international treaties, would be further reinforced. It would become very difficult to regulate the trade in academic institutions, programs, degrees, or products across international borders. Those wishing to engage in such imports and exports would have recourse to international tribunals and legal action. At present the jurisdiction over higher education is entirely in the hands of national authorities.

The questions raised by this initiative relate to the very idea of higher education and to the future of academe especially in the developing nations and in smaller countries. How would countries, or individual universities, maintain their academic independence in a world in which they had minimal practical and legal control over the import or export of higher education? How would accreditation or quality control be carried out? Would there be a distinction made between public or private nonprofit higher education - the "gold standard" for centuries—and the new and aggressive for-profit sector? Would wealthy profit-driven multinationals force other higher education institutions out of business? Would a full-time professoriate with claims to academic freedom survive? One thing is very clear-once the universities are part of the WTO jurisdiction, autonomy would be severely compromised and advanced education and research would become just another product subject to international treaties and bureaucratic regulations. 
The greatest negative impact of WTO control over higher education would occur in the developing countries. These countries have the greatest need for academic institutions that can contribute to national development, produce research relevant to local needs, and participate in the strengthening of civil society. Once universities in developing countries are subject to an international academic marketplace regulated by the WTO, they would be swamped by overseas institutions and programs intent on earning a profit but not in contributing to national development. It is not clear that accrediting and quality control mechanisms that now exist in many countries would be permitted, at least as they relate to transnational educational providers.

\section{The proposed WTO initiatives bring all of the pressures now being felt by uni- versities worldwide into sharp focus.}

Who Should Control Higher Education?

Every country needs to maintain essential control over its academic institutions. At the same time, individual universities need an adequate degree of autonomy and academic freedom if they are to flourish. For centuries, traditional universities have performed a central function in society. While that function has changed over time, it has not disappeared. The challenge of the new initiatives and globalization generally is one of the most serious since the medieval universities faced the rise of nationalism and the Protestant Reformation in the 16th century. For almost a millennium, universities have defined themselves as institutions with a core educational mission and a common understanding of the values of academe. For much of this period, universities were understood not only as institutions that provided education in practical fields of knowledge but as central cultural institutions in society. In the 19th century, science and research were added to the academic mission. Universities were recognized as special institutions by society precisely because their goals went beyond everyday commerce. Now, all of this is under threat.

The academic community itself is in considerable part responsible for the changes. Some universities have all too willingly allowed themselves to be caught up in commercial activities and to compromise their traditional roles. The establishment of "for-profit" subsidiaries by such renowned institutions as New York University and Columbia University is symbolic of these compromises. Monash University, a well-known Australian institution, is establishing profit making branches overseas. The University of Chicago's business school has opened branches in Spain and Singapore. Universities in China devote much of their attention to providing profit-making consulting and setting up technology companies. Many universities have gone "on-line" to sell their courses and degrees to customers in all parts of the world.

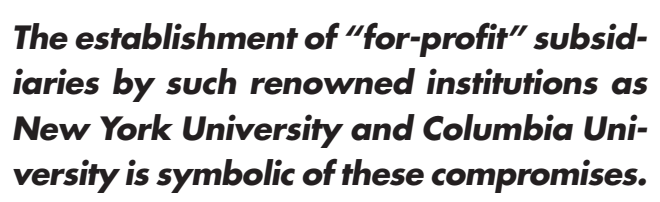

If universities are to survive as intellectual institutions, they must pay close attention to their core responsibilities of teaching, learning, and research. Maintaining loyalty to traditional academic values will not be easy, but the costs of growing commercialization are much greater.

Governments and other public authorities need to give the universities the support they need to fulfill their mission. Constantly squeezing the budget, demanding ever greater accountability, and insisting that the university fundamentally change its goals does not in the long run serve the public interest. The public must also respect the underlying values of higher education.

The developing countries have special academic needs that must be protected, and any WTO-style treaty would inevitably harm the emerging academic systems of the developing countries. Third World universities are now involved in many international relationships, but these arrangements are based on national needs and allow choice among programs and partners.

The proposed W'TO initiatives bring all of the pressures now being felt by universities worldwide into sharp focus. If higher education worldwide were subject to the strictures of the WTO, academe would be significantly altered. The idea that the university serves a broad public good would be weakened, and the universities would be subject to all of the commercial pressures of the marketplace - a marketplace enforced by international treaties and legal requirements. The goal of having the university contribute to national development and the strengthening of civil society in developing countries would be impossible to fulfill. Universities are indeed special institutions with a long history and a societal mission that deserve support. Subjecting academe to the rigors of a WTO-enforced marketplace would destroy one of the most valuable institutions in any society.

Reprinted in revised form with permission from the Chronicle of Higher Education. 